上式における $k_{2}$ (前報の Table-2) と $k_{3}(\mathbf{T a b l e}-3)$ の各反応温度における相違は Diels-Alder 反応におい てジェンとしては共通の trans, trans-共役オクタデカ ジェン酸メチルが働くので, ジェノファイルとしての trans, trans-共役体と cis, trans-共役体のジェノファイ ルとしての反応性の違いによるものと考えられる。その ジェノファイルとしての反応性は速度定数 $k_{2}$ と $k_{3}$ の相 違から trans, trans-共役体は cis, trans-共役体よりも $270^{\circ} \mathrm{C}$ において約 3 倍, $290^{\circ} \mathrm{C}$ において約 2 倍の反応性 を持っている。また，その活性化エネルギーにおいて約 $6 \mathrm{kcal} / \mathrm{mol}$ の差が認められた。

本実験に和ける試料の提供を受けた綜研化学株式会社に厚く 和礼を申し上げます。また，本報文は昭和 42 年 10 月，第 6 回 油化学討論会 (名古屋) で講演した。

(昭和 43 年 3 月 19 日受理)

\section{文献}

1) 橋本, 鈴木, 田辺 油化学, 投稿中

2) R.F. Raschke et al., Ind. Eng. Chem., 44, 1113: (1952)

3) P.L. Nicohls, = Jr. et al., J. Am. Chem. Soc., 73, 247 (1951)

4) 橋本, 椎名, 油化学, 9, 376 (1960)

5) 橋本, 鈴木, 田辺, 油化学, 17, 299 (1968)

6) R.F. Paschke et al., J. Am. Oil Chemists'Soc., 41 . 724 (1964)

7) V.V. Katarov, V.A. Lutsenko, International Chem. Eng. (USSR), 5, 623 (1965)

8) R.O. Butterfield et al., J. Am. Oil Chemists' Soc., 41, 29 (1964)

9) J.C. Cowan, J. Am. Oil Chemists', Soc., 31, 529 (1954)

10) J.C. Cowan, J. Am. Oil Chemists' Soc., 39, 535, (1962)

\title{
チオールとアルコールの脱水縮合による スルフィドの合成
}

\author{
中 野 紘一・板 橋 国夫 \\ 日本大学理工学部（東京都千代田区神田駿河台）
}

The Synthesis of Sulfides by Dehydration of Alcohols with Thiol

\author{
Kōichi NAKANO and Kunio ITABASHI \\ Faculty of Science \& Engineering, Nihon University \\ (Kanda-Surugadai, Chiyoda-ku, Tokyo)
}

The synthesis of sulfides by the dehydration of various alcohols with $n$-octanethiol (1) has been investigated.

The reactions proceed in the presence of acid catalysts, and the use of Lewis acids as catalysts was usually more effective in the yield of sulfides than protonic acids.

The reactivity of butanols was in the order of tertiary $>$ secondary $>$ primary alcohol, but the reaction of (1) with primary alcohol was scarce.

The effect of Lewis acids for the reaction of benzylalcohol (2) with (1) was in the order $\mathrm{ZnCl}_{2}>\mathrm{SbCl}_{3}>\mathrm{SnCl}_{4}>\mathrm{FeCl}_{3}>\mathrm{AlCl}_{3}$.

The rates of formation of the sulfide and activation energy were measured for the reaction of (2) with (1). The reaction was of the first-order with respect to the concentration of (2) but it was independent of (1). The apparent activation energy was about $26.3 \mathrm{kcal} / \mathrm{mol}$.

From the above results, it seems that the formation of carbonium ion takes a rate-determing step in the reaction of (2) with (1).

\section{1 緒 言}

スルフィドの合成法としては総説 ${ }^{1)} に も$ 見られるよう に, 主として硫化アルカリのアルキル化, メルカプチド
のアルキル化，二重結合へのチオールの付加などによる ものがあるが，チオールとアルコールの脱水縮合による スルフィドの生成は二三の例が知られているのみで女 る。すなわちベンズヒドロール21，第三ブタノールとチ 


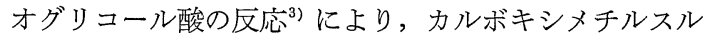
フィドが得られているが，第一，第二アルコールについ ての例は見当たらない。

本研究においては, 各種アルコールと $n$-オクタンチ オールの反応によるスルフィドの生成について検討を加 え, 酸触媒の効果について調べた。

\section{2 実 験 方 法}

\section{$2 \cdot 1$ 試料}

アルコール類は市販の試薬を, $n$-オクタンチオールは 花王石鈿株式会社製のものをそれぞれ精留し，Table-1 の物理定数を有するものを用い，ほかの試薬は市販一級 品をそのまま使用した。

Table-1 Properties of materials.

\begin{tabular}{l|c|l}
\hline \multicolumn{1}{c|}{ Materials } & $\mathrm{bp}\left({ }^{\circ} \mathrm{C} / \mathrm{mmHg}\right)$ & \multicolumn{1}{c}{$n_{\mathrm{D}}^{16}$} \\
\hline$n$-Octanethiol & $95 / 28$ & 1.4547 \\
$n$-Butanol & $117 / 760$ & $1.4001\left(15^{\circ} \mathrm{C}\right)$ \\
sec-Butanol & $99 / 760$ & 1.3978 \\
tert-Butanol & $82 \sim 83 / 760$ & 1.3871 \\
Cyclohexanol & $92 \sim 93 / 100$ & 1.4665 \\
Benzylalcohol & $75 \sim 76 / 23$ & 1.5412 \\
$\beta$-Phenylethyl alcohol & $96 \sim 100 / 12$ & $1.5319\left(15^{\circ} \mathrm{C}\right)$ \\
\hline
\end{tabular}

\section{$2 \cdot 2$ 反応の方法}

カキマゼ機, 還流冷却器, 温度計をつけた内容 $200 \mathrm{~m} l$ の三ツロフラスコに, $n$-オクタンチオール，アルコール 各 $0.1 \mathrm{~mol}$, 触媒 $1 \sim 5 \mathrm{~g}$ を入れ, $100^{\circ} \mathrm{C}$ で $5 \mathrm{hr}$ かきま ぜながら反応を行なった。

\section{$2 \cdot 3$ 反応生成物の処理}

反応終了後, 反応液を水洗し触媒を除去し, 油層を分 取した。洗液はエーテルで 2 回抽出し, エーテル層を油 層と合わせ無水硫酸ナトリウムで脱水乾燥した。エーテ ルを留去し，その残分を生成物とした。

生成物は窒素気流中で精留し, bp $95^{\circ} \mathrm{C} / 25 \mathrm{mmHg}$ ま での留分と残分とに分けた。留分は未反応のアルコール とチオールで，チオールはヨウ素滴定法により4)，チオ 一ルの定量を行なった。残分は対応するスルフィドであ り，それぞれの方法により生成物の確認，ガスクロマト

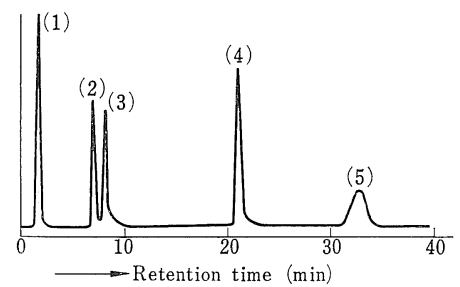

(1) Octanethiol (2) tert-Butyloctylsulfide

(3) sec-Butyloctylsulfide (4)Cyclohexyloctylsulfide

(5) Benzyloctylsulfide

Column: Thermol-2; Carrier gas: He $40 \mathrm{ml} / \mathrm{min}$; Temperature: Column $220^{\circ} \mathrm{C}$, Injector $340^{\circ} \mathrm{C}$ Detector $240^{\circ} \mathrm{C}$

Fig.-1 Gas chromatogram of standard materials.
グラフィーによる定量を行なった（Fig.-1)。

\section{$2 \cdot 4$ 各坐成物の確認}

$2 \cdot 4 \cdot 1$ ベンジルオクチルスルフィド

bp $181 \sim 182^{\circ} \mathrm{C} / 5 \mathrm{mmHg}, n_{\mathrm{D}}^{15} 1.5161$ ，この留分を Reinbolt, Giesbrecht の方法 ${ }^{5}$ に準して酸化して, mp 67〜 $68^{\circ} \mathrm{C}$ のスルホンに変えて確認した。すなおちスルフィ ドを約 3 倍量の水酢酸に溶解し，50〜 $60^{\circ} \mathrm{C}$ でかきまぜ ながら過剩の $30 \%$ 過酸化水素水を滴加して酸化した。 反応後水中に注ぎ，得られた粗結晶をエタノールで再結 晶した。元素分析值 C $67.30 \%, \mathrm{H} 8.95 \%\left(\mathrm{C}_{15} \mathrm{H}_{24} \mathrm{O}_{2} \mathrm{~S}\right.$ としての計算值 C $67.12 \%, \mathrm{H} 9.01 \%) 。$

また，塩化ベンジルとナトリウムメルカプチドから別 途合成したスルフィド，スルホンとの混融点および IR が一致した。

$2 \cdot 4 \cdot 2$ 第二ブチルオクチルスルフィド

$\mathrm{bp} 123^{\circ} \mathrm{C} / 4 \mathrm{mmHg}$ (文献值 ${ }^{6}$ ) $\mathrm{bp} 78 \sim 80^{\circ} \mathrm{C} / 0.3 \mathrm{mmHg}$ ), $n_{\mathrm{D}}^{15} 1.4588$ (文献值 ${ }^{6)} n_{\mathrm{D}}^{25} 1.4453$ ) など物理定数が文献值 と一致した。スルホンの融点は $30^{\circ} \mathrm{C}$ 以下であった。別 途合成によるスルフィドの IR が一致した。

$2 \cdot 4 \cdot 3$ 第三ブチルオクチルスルフィド

bp $113 \sim 115^{\circ} \mathrm{C} / 4 \mathrm{mmHg}$ (文献值 ${ }^{6)}$ bp $79 \sim 82^{\circ} \mathrm{C} / 0.6$ $\mathrm{mmHg}$ ), $n_{\mathrm{D}}^{15} 1.4619$ (文献值 ${ }^{6)} n_{\mathrm{D}}^{25} 1.4530$ )。

$2 \cdot 4 \cdot 4$ シクロヘキシルオクチルスルフィド

bp $142^{\circ} \mathrm{C} / 7 \mathrm{mmHg}, n_{\mathrm{D}}^{15} 1.4792$ ，スルホン $\mathrm{mp} 28 \sim 29$ ${ }^{\circ} \mathrm{C}$, 元素分析值 $\mathrm{C} 64.89 \%, \mathrm{H} 10.76 \%\left(\mathrm{C}_{14} \mathrm{H}_{28} \mathrm{O}_{2} \mathrm{~S}\right.$ とし ての計算值 C $64.56 \%$, H 10.86\%)。

$2 \cdot 4 \cdot 5 \quad \beta$ ーフェルェチルオクチルスルフィド

bp $178 \sim 179^{\circ} \mathrm{C} / 4 \mathrm{mmHg}, n_{\mathrm{D}}^{15} 1.5099$, スルホン $\mathrm{mp} 44$ $\sim 45^{\circ} \mathrm{C}$, 元素分析值 $\mathrm{C} 67.43 \%, \mathrm{H} 9.84 \%\left(\mathrm{C}_{16} \mathrm{H}_{26} \mathrm{O}_{2} \mathrm{~S}\right.$ としての計算值 C $68.04 \%, H 9.28 \%$ )。

\section{3 結果と考察}

\section{1 各種アルコールの反応}

n-オクタンチオールと各種アルコールとの反応の条件 と結果については Table-2 にまとめた。

反応には酸触媒が必要であって，一般にルイス酸を用 いた方がプロトン酸に比べてスルフィドの収率は良好で あった。

ブタノールの反応性は第三>第二>第一級の順で, 第一級の場合スルフィドは認められなかった。

これらの反応性はカルボニウムイオン生成の容易さの 順序 ${ }^{7)}$ と一致している。

なお第一アルコールが反応するためには加圧下 $200^{\circ} \mathrm{C}$ 以上が必要であった

ブタノールの反応経路は次式のように考えられる。す なわち陽性炭素へのチオールの求核的反応 $[(1),(2)$ 式 $]$ と脱水生成したオンフィンへのチオールの付加反応 $[(3),(4)]$ に分けられる。 
Table-2 Reaction conditions and results. Octanethiolalcohol $0.1 \mathrm{~mol}$; Temp. $100^{\circ} \mathrm{C}$, Time $5 \mathrm{hr}$.

\begin{tabular}{|c|c|c|}
\hline Alcohol & Catalyst (g) & $\begin{array}{l}\text { Yield of sulfide } \\
(\%)\end{array}$ \\
\hline \multirow[t]{2}{*}{$n$-Butanol } & PTS* (1) & - \\
\hline & $\mathrm{ZnCl}_{2}$ & - \\
\hline \multirow[t]{2}{*}{ sec-Butanol } & PTS (5) & trace \\
\hline & $\mathrm{ZnCl}_{2}$ & 24.9 \\
\hline \multirow[t]{3}{*}{ tert-Butanol } & PTS & 21.3 \\
\hline & PTS (5) & 40.6 \\
\hline & $\mathrm{ZnCl}_{2} * *(5)$ & 87.6 \\
\hline \multirow[t]{3}{*}{ Cyclohexanol } & PTS (1) & trace \\
\hline & $\mathrm{ZnCl}_{2}$ & 35.1 \\
\hline & $\mathrm{FeCl}_{3}$ & 12.4 \\
\hline \multirow[t]{7}{*}{ Benzylalcohol } & PTS & 45.0 \\
\hline & PTS & 56.8 \\
\hline & PTS & 64.4 \\
\hline & PTS & 68.2 \\
\hline & $\mathrm{ZnCl}_{2}$ & 97.5 \\
\hline & $\mathrm{FeCl}_{3}$ & 86.7 \\
\hline & $\mathrm{PPA}^{* * *}(1)$ & 17.8 \\
\hline$\beta$-Phenylethylalcohol & $\mathrm{ZnCl}_{2}$ & 4.4 \\
\hline
\end{tabular}

$* p$-Toluenesulfonic acid ** Temp. $80^{\circ} \mathrm{C}$ *** Polyphosphoric acid

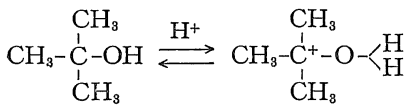

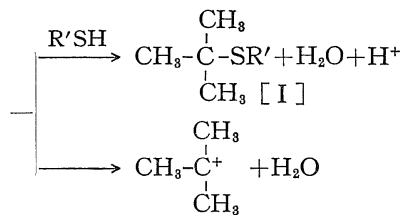

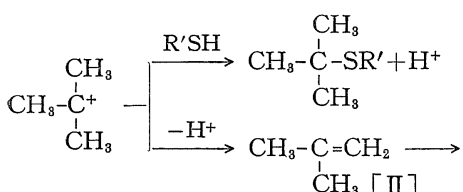

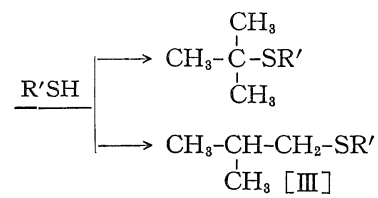

第三ブタノールの反応において, $\mathrm{ZnCl}_{2}$ の存在では, 第三ブチルオクチルスルフィド $[\mathrm{I}]$ のみが得られたが PTS の場合はそのほか少量の iso-ブチルオクチルスル フィド [III] が認められた。［III］は PTS 触媒では脱 水によりインブテン [II] を生じ，これに対してチオー ルが付加反応した $[(4)$ 式]ことを示している。

第二ブタノールの場合は，PTS の存在下で封管中 $170^{\circ} \mathrm{C}$ の反応においても生成物は第二ブチルオクチルス ルフィドのみであって，脱水反応が起こらないことがわ かった。 $\mathrm{ZnCl}_{2}$ の反応でも同様であった。
ベンジルアルコールの反応は最も容易であるが，PTS 触媒では常にベンジルエーテルが副生した。PTS 添加 量, 反応温度と生成物収率の関係を Fig。-2, 3 に示し た。 $100^{\circ} \mathrm{C}$ においてベンジルオクチルスルフィドの収率 は, PTS の添加量の増加とともに増したが, ベンジル エーテルの収率は 15 20\% の範囲で，あまり変化しな かった。スルフィドの生成しやすい高温ではエーテルの 収率が減少し， $170^{\circ} \mathrm{C}$ ではエーテルはわずかであった。

PTS に比ベルイス酸は有効でいずれも好収率でスル フィドを得た。それらの触媒効果は Table-3 に示すよ うで, $\mathrm{ZnCl}_{2}>\mathrm{SbCl}_{3}>\mathrm{SnCl}_{4}>\mathrm{FeCl}_{3}>\mathrm{AlCl}_{3}$ の順

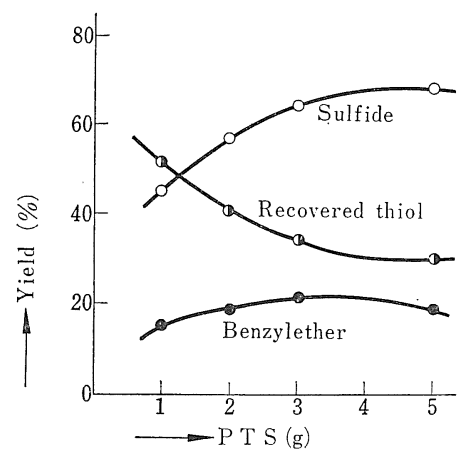

Fig.-2 Effect of addition of PTS $\left(100^{\circ} \mathrm{C}, 5 \mathrm{hr}\right)$.

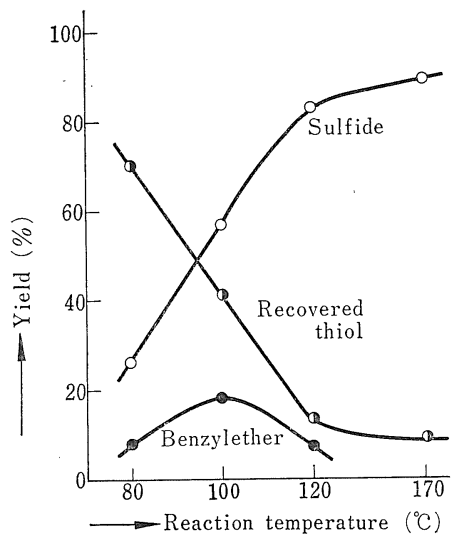

Fig.-3 Influence of temperature (PTS $2 \mathrm{~g}, 5 \mathrm{hr}$ ).

Table-3 Effect of Lewis acids. Lewis acid $0.03 \mathrm{~mol}$; benzylalcohol, $n$-octane thiol $0.1 \mathrm{~mol} 100^{\circ} \mathrm{C}, 5 \mathrm{hr}$.

\begin{tabular}{|c|c|c|c|c|}
\hline \multirow{2}{*}{$\begin{array}{l}\text { Lewis } \\
\text { acids }\end{array}$} & \multicolumn{4}{|c|}{ Yield of product $(\%)$} \\
\hline & Sulfide & $\begin{array}{c}\text { Benzyl- } \\
\text { ether }\end{array}$ & $\begin{array}{l}\text { Dioctyl- } \\
\text { disulfide }\end{array}$ & Others \\
\hline $\mathrm{ZnCl}_{2}$ & 98.1 & H & - & \\
\hline $\mathrm{SbCl}_{3}$ & 94.2 & $H$ & 4.0 & \\
\hline $\mathrm{SnCl}_{4}$ & 91.2 & - & 6.3 & \\
\hline $\mathrm{FeCl}_{3}$ & 86.7 & - & 11.7 & \\
\hline $\mathrm{AlCl}_{3}$ & 82.5 & - & - & \\
\hline $\mathrm{TiCl}_{3}$ & 30.7 & + & - & $\left\{\begin{array}{c}\text { Benzyl- } \\
\text { chloride } \\
36.6\end{array}\right.$ \\
\hline
\end{tabular}




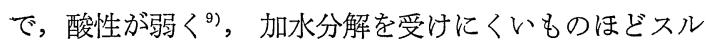
フィドの収率は良好であった。

またベンジルエーテルはほとんど生成しなかったが， ジオクチルジスルフィドが副生し, $\mathrm{FeCl}_{3}$ では $10 \%$ を 越えた。これは $\mathrm{FeCl}_{3}$ による酸化作用の結果であろう。

$\mathrm{TiCl}_{3}$ では多量の塩化ベンジルを生じ, スルフィドの 収率は $30 \%$ に止まった。

\section{2 ベンジルオクチルスルフィド生成の速さ}

トルエン溶媒中ベンジルアルコール，チオールの濃度 を変え, PTS を触媒として反応の速さを調べた。この 際チオール過剩ではスルフィドのみが，アルコール過剩 の場合でもエーテルが副生するにすぎなかったので，チ オールの減少量 ${ }^{4)}$ とガスクロマトグラフィーとの結果と を合わせて反応速度を測定した。

アルコール過剩での反応の速さは Fig。-4 のようにほ ほ直線的に進行し, チオールの初濃度を変えてもほとん ど変化しなかった。これらのことから初期反応速度はチ オール濃度に関してほぼ 0 次であることがわかった。

またチオール過剩での反応において，一次反応の速度

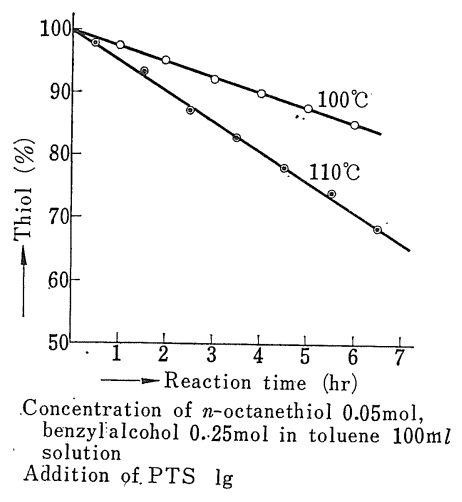

Fig.-4 Cocentration vs. time curves.

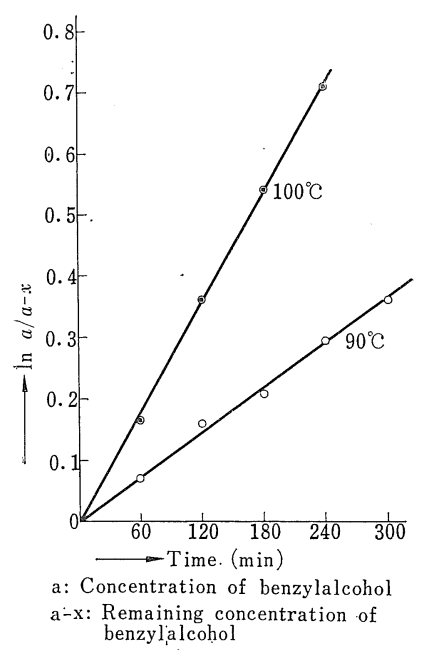

Fig.-5 First order plots.
式に当てはめると Fig.-5 亿示すように直線となるので アルコール濃度に関して一次であることがわかった。

90 $110^{\circ} \mathrm{C}$ に打いてそれぞれの反応速度定数 $k$ を求め ると Table-4 の結果が得られた。これらの結果から， Arrhenius 式に従い見かけの活性化エネルギーを求める と(Fig.-6), 約 $26.3 \mathrm{kcal} / \mathrm{mol}$ の值を得た。

Table-4 Rate constants and Arrhenius activation energy.

\begin{tabular}{c|c|c}
\hline Temp. $\left({ }^{\circ} \mathrm{C}\right)$ & $k\left(\mathrm{~min}^{-1}\right)$ & $E(\mathrm{kcal} / \mathrm{mol})$ \\
\hline 90 & $1.2 \times 10^{-8}$ & \\
100 & $2.9 \times 10^{-3}$ & \\
110 & $7.7 \times 10^{-3}$ & \\
\hline
\end{tabular}

Concentration of octanethiol $0.20 \mathrm{~mol}$, benzylalcohol 0.05 $\mathrm{mol}$ in toluene $100 \mathrm{~m} l$ solution.

Addition of PTS $1 \mathrm{~g}$.

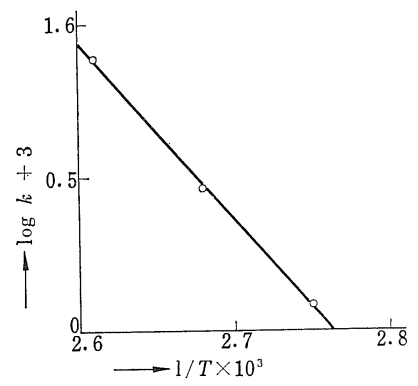

Fig.-6 Arrhenius plot.

\section{$3 \cdot 3 \beta$-置換アルコールとの反応}

第一ブタノールでは反応が起こらなかったが， $\beta$-位に 置換基を有する第一アルコールについて, $\mathrm{ZnCl}_{2} 5 \mathrm{~g}$ の 存在下，Table-2 の反応条件で反応を試みた。

$\beta$-置換エタノールとしては, $\beta$-フェニル-(a), $\beta$-メト キシー(b), $\beta$-シアノエタノール (c), イソブタノール （d）を用いたが，(a)のみが反応し，その他は反応しな かった。これは生成したカルボニウムイオンがつぎに示 すような共鳴により安定化するためと思われる ${ }^{10)}$ 。

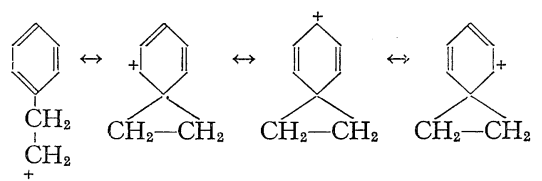

以上の結果を総括すると, 本反応はチオールのアルコ 一ルに対する求核置換反応で, ベンジルアルコールの PTS 触媒存在での反応に拉いては, カルボニウムイオ ン生成が律速段階と思われる。

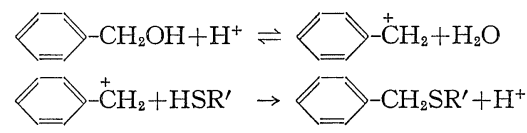

最後に本研究を行なうに当たりまして御指導いただきました 日本大学理工学部, 庄野信司教授, 実験に協力せられた田畑雅利 氏および試料を恵与された花王石喃株式会社に深謝いたします。 (昭和 43 年 4 月 17 日受理) 


\section{文献}

1) a) R.B. Wagner, H.D. Zook" Synthetic Organic Chemistry" p. 787 (1953), John Wiley, New York

b) 日本化学会編 “実験化学講座” 20 , 有機化合物の合成 II, p. 57 (1956), 丸善, 東京

2) R. Dahlbom, L.E. Oesterberg, Acta Chem. Scand., 2, 856 (1948)

3) N. Hellström, T. Lauritzson, Ber., 1999, 2003 (1936)

4) J.W. Kimball et al., J. Am. Chem. Soc., 43, 1199 (1921)

5) H. Reinboldt, E. Giesbrecht, J. Am. Chem. Soc.,
68, 973 (1946)

6) W.E. Truce, J.J. Breiter, J. Am. Chem. Soc., 1621 (1921)

7） E.R. Alexander, 後藤ら訳 “イオン有機反応要説” p.38 (1957), 南江堂, 東京

8）板橋, 中野 “第 6 回油化学討論会講演要旨集” p. 27 (1967)

9）田部, 竹下 “酸塩基触媒” p. 116 (1965), 産業図書, 東 京

10） P. Sykes, 久保田訳 “有機反応機構(上)” p. 90 (1964), 東京化学同人, 東京

\title{
酸化防止剤飞関する研究(第 1 報)
}

\section{ヒドロキノン誘導体の酸化防止性について}

\author{
原田 基 夫 \\ 国立衛生試験所（東京都世田谷区上用賀）
}

Studies on Antioxidants. I.

Antioxidant Ability of Hydroquinone Derivatives

\author{
Moto-o HARADA \\ Material Institute of Hygienic Sciences \\ (Kamiyōga-machi, Setagaya-ku, Tokyo)
}

Antioxidant ability of alkylen-bis-phenol derivatives was investigated. The methyl ester of fatty acids used for the test was prepared by alkali-catalyzed methanolysis of soybeen oil, followed by distillation in vacuum under nitrogen stream. The derivatives were added to the methyl ester at $0.01 \%$ level, and were measured by active oxygen method (AOM) and electron donnor effect.

$p$-Dimethoxy derivatives ( I, V, VI) did not show any effect. Hydroxy derivatives (II, III, IV, VII) improved the oxidative stability of the methyl ester, but the effect of derivatives containing carbonyl in the chain (II, III, IV) was less than half of the effect of the sample without containing carbonyl group (VII), 1, 16-bis (2, 5-dihydroxyphenyl) hexadecane (BDPH). The difference observed in the antioxidant ability may probably due to a result of hydrogen-bonding between hydroxyl and carbonyl radical, which reduces hydrogen or electron donative ability from the molecule.

The antioxidant ability of BDPH was also compared with the commonly used antioxidant for vegetable oils, such as nordihyroguaiaretic acid (NDGA), $\alpha$-tocopherol ( $\alpha$-Toc), propyl gallate (PG), ethyl protocatecuate (EP), buthylated hydroxyanisole (BHA) and dibutyl hydroxytoluen (BHT). $\mathrm{BDPH}$ was more effective than these antioxidants. The effect of BDPH increased proportionally with the concentration within 0.005 to $0.1 \%$.

Additivity in the antioxidant ability of $\mathrm{BDPH}$ with other typical antioxidants was observed at $0.01 \%$ levels. The systems of BDPH plus BHT, and BDPH plus $\alpha$-Toc showed super-additivities, while BDPH plus NDGA was less effective than EDPH plus BHA.

From these observations BDPH might be a usefull antioxidant practically.

\section{1 緒言 われわれの食生活において油脂の酸化防止はきわめて}

重要な問題である。なぜなら油脂の酸化はその風味を劣 化させるばかりでなく，栄養価を低下五させ，ついには 毒性 ${ }^{2)}$ を示すようになるからである。これらのために従 